\title{
The Application of Wave Energy Converter in Hybrid Energy System
}

\author{
Song Ding*, Duanfeng Han and Yingfei Zan \\ College of Shipbuilding Engineering, Harbin Engineering University, Harbin 150001, China
}

\begin{abstract}
As a promising renewable energy resource, wave energy is having more and more interest in both academic research and industry development. In this paper, all subcategories of WECs are presented and discussed with their main feathers. Although there are numerous subcategories of wave energy converter (WEC), wave energy exploitation still haven't reached its commercial stage. Many specific reasons and disadvantages limit its development. To overcome the disadvantages and improve overall performance of WEC, a hybrid concept combining WEC and floating wind turbine is proposed. The specific application of WEC in this hybrid system is also analyzed.
\end{abstract}

Keywords: Hybrid system, power performance, renewable energy, wave energy converter.

\section{INTRODUCTION}

As the world population increased and our society is more and more industrialized, the demand for energy is growing fast. The world's population currently consumes 15 TW of power that is predicted to increase to $30 \mathrm{TW}$ by 2050 . People have been depending on fossil fuels as their major source of energy since the past century. However, fossil fuels continue to be depleted and its negative environmental impact is very alarming. The environmental and ecological impacts of "Green House Gases" (GHG) and global warming are now universally acknowledged, as are their economic implications. Therefore, the importance of finding new clean renewable energy is emphasized for promising future of all human being.

In all kinds of renewable energy, wave energy has shown great potential in the following years. In some terms, Wave energy power is enormous and more reliable than other renewable resources such as solar and wind energy because its density $(2-3 \mathrm{~kW} / \mathrm{m} 2)$ is greater (wind $0.4-0.6 \mathrm{~kW} / \mathrm{m} 2$; solar $0.1-0.2 \mathrm{~kW} / \mathrm{m} 2$ ). Although it is still immature compared to other renewable technologies, the wave energy is having more and more interest and support as a promising renewable resource to replace part of the energy supply. The possibility of converting wave energy into usable energy has inspired numerous inventors.

More than one thousand prototypes of WEC have been developed over the years $[1,2]$ and this number is not likely to decrease since new concepts and technologies keep emerged and replace the non-ideal ones. Several methods have been proposed to classify wave energy systems, according to location, to size and to working principle. Therefore, each WEC can be classified into several groups depending on its features. Among all categories of WECs, some prototypes have been built on a large scale, and have been tested in actual sea conditions. However, until now, there is still no one specific type of WEC shows outstanding performance overwhelms others and reaches its fully commercial stage.

One reason hinders WEC's development is that the WEC's energy transfer efficiency is relatively lower than other renewable energy sources which will lead a poor costbenefit. Additionally, since the lack of available space, noise, shade and visual pollution in onshore and near-shore areas, high quality resource in offshore is definitely more suitable for WEC. However, for offshore devices the survival performance in extreme condition could be a challenge for WEC's design. In extreme mode, security is more important than power performance. Furthermore, the cost of offshore installation, operation and maintenance can also be very expensive and difficult. Based the above statements, the higher cost benefit and outstanding motion performance requirement in survival situation are two mainly reasons hinder WEC's development in its initial stage.

To overcome these disadvantages, one consideration is to combine the wave energy converter with floating wind turbine on one platform and absorb wind and wave energy together. There are many benefits by doing this. Mooring system, electrical infrastructure, and other components are being shared with the existing floating wind turbine structure. The overall cost of installation, operation and maintenance can be decreased. Under the unexpected situation, when the wind does not blow or is too strong, or when the wind turbine is subject to a temporary failure, the wave energy device could still absorb and transfer wave power and make the overall power output smoothly. Ideally, the WEC should be integrated so as to reduce the overall motion response of the platform, and could thus have a stabilizing effect on the whole system. The wind energy generation component of the system could come out enhanced.

This paper gives a brief introduction of wave energy converter with all its subcategories. Different types of WECs' advantages and disadvantages are analyzed and compared. Then the hybrid concept which combine wave 
energy convert with floating wind turbine is pointed out with details and possible combinations.

\section{WAVE ENERGY CONVERTER}

Several literature reviews of WEC devices have been published providing information about various aspects of the technology [3-7]. These devices, in general terms, can be classified according to three characteristics: working principle, location and size. Therefore, each WEC can be classified into several groups depending on its features. In this paper, the classification related to working principle is mostly presented since working principle is the essential difference among WECs. The subcategories of WEC are sketched in Fig. (1).

\subsection{Working Principle}

Oscillating water column (OWC): These converters comprise a partly submerged concrete or steel structure, open below the water surface, inside which air is trapped above the water free surface as shown in A1 of Fig. (1). The oscillating motion of the internal free surface produced by the incident waves makes the air to flow through a turbine that drives an electrical generator. The OWC is usually located on the shore line or near shore. In specific, the axialflow wells turbine, invented in the mid 1970s, has the advantage of not requiring rectifying values. The air flow drives the turbine which rotates always in the same direction even though the air flow is bidirectional. It has been used in most prototypes.
Oscillating body systems: These converters are basically offshore devices, either floating or (more rarely) fully submerged. This type of devices is based on a floating body which is moved by the waves. The oscillatory movement can be vertical, horizontal, pitch or a combination of them. Additionally, this movement can be induced either by an absolute motion between the floating body and an external fixed reference or on two or more bodies. Therefore some typical subcategories are single-body heaving buoys, twobody heaving systems, fully submerged heaving systems, pitching devices, bottom-hinged systems and many-body systems. As shown, A2 in Fig. (1) is the sketch of a singlebody heaving buoy.

Overtopping converters: These converters capture the water that is close to the wave crest and introduce it, by over spilling, into a reservoir where it is stored at a level higher than the average free-surface level of the surrounding sea as shown in A3 of Fig. (1). Then the potential energy of the stored water is converted into useful energy through more or less conventional low-head hydraulic turbines. The hydrodynamics of overtopping devices is strongly nonlinear, and, unlike the cases of oscillating body and OWC wave energy converters, cannot be addressed by linear water wave theory.

\subsection{Location}

Onshore and nearshore devices: As illustrated in B of Fig. (1), these converters are located in shallow water, integrated in a breakwater likes, in a dam, or fixed to a cliff, or rest on the seabed. The main advantage of these

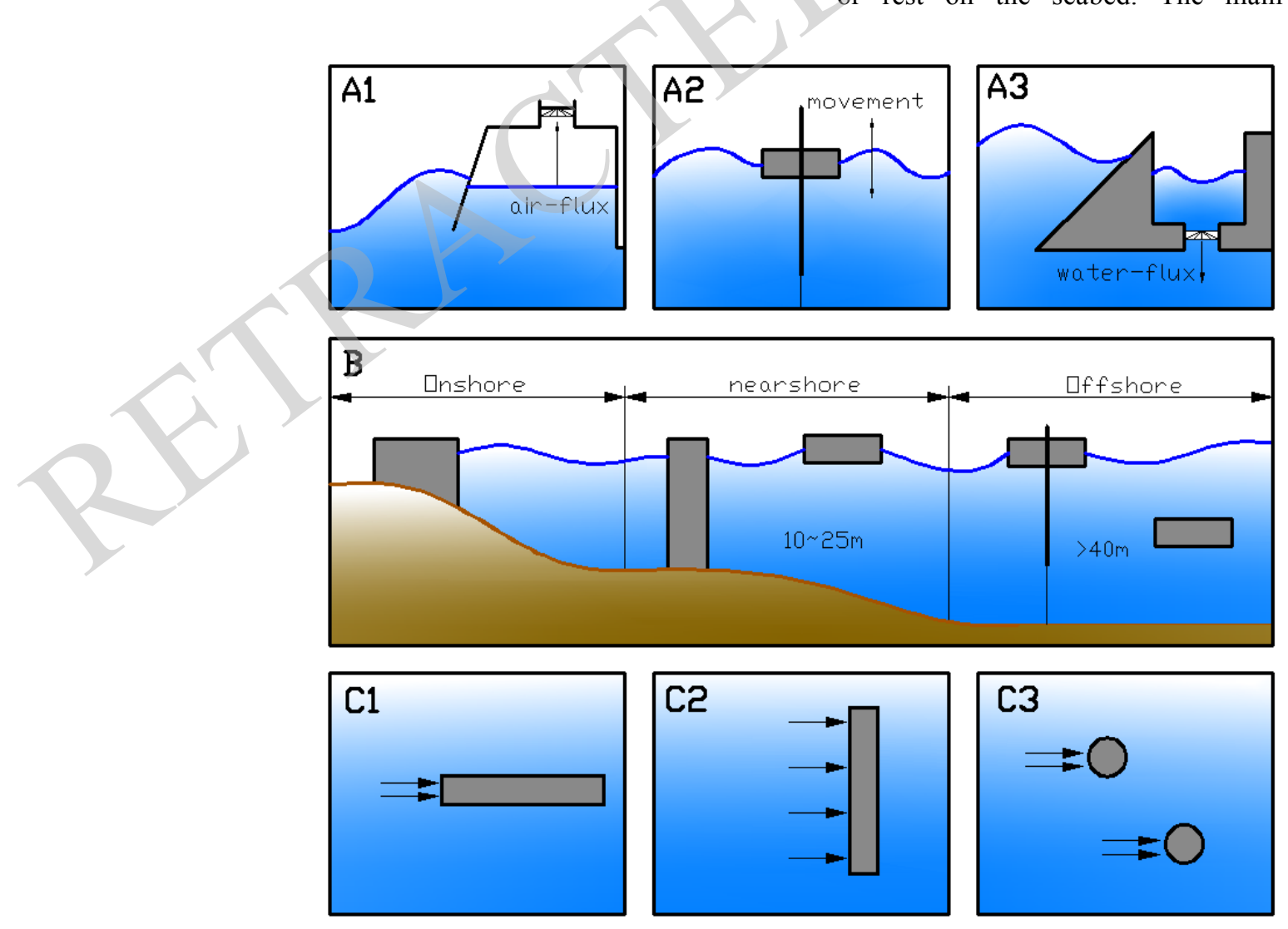

Fig. (1). Subcategories of WEC (A1-OWC; A2-Oscillating Body System; A3-Overtopping Converter; B-Onshore, Nearshore and Offshore devices: C1-Attenuator; C2-Point Absorber; C3- Terminator). 
converters is their easy maintenance and installation since in most cases the location is accessible. Furthermore, these devices do not need complex mooring systems or a long length of sea cable to connect the WEC to the grid. However, waves contain less energy at the shoreline since their interaction with seabed. The onshore devices also lead to environmental problems since the shore of the sea is reshaped.

Offshore devices: As illustrated in B of Fig. (1), these converters are located in deep water, and usually built in floating or submerged structures moored to the seabed. Offshore wave energy converters are in general more complex compared with onshore or near shore devices. This together with additional problems associated with mooring, access for maintenance and the need of long underwater electrical cables, has hindered their development, and only recently some systems have reached, or some close to, the full-scale demonstration stage.

\subsection{Size and Direction}

Attenuator: These converters are long structures when compared with wave length. Placed in parallel with respect to the wave direction, attenuator attenuates the wave as shown in $\mathrm{C} 1$ of Fig. (1). Attenuators are composed by a series of cylindrical sections linked together by flexible hinged joints that allow these individual sections to rotate relative to each other. Pelamis $750 \mathrm{~kW}$ prototype converter is a typical example of this type of devices.

Point absorber: These converters' size is smaller than the wave length. Wave energy can be absorbed in all directions through its movements as shown in B2 of Fig. (1). These devices convert the up-and-down pitching motion of the waves into their own movements (rotary or oscillatory) and then transfer the kinetic energy into electricity power.

Terminator: These converters are similar to Attenuators, as they are also long structures. However, these ones are placed vertical to the direction of wave propagation and, in essence, "terminate" the wave action as shown in C3 of Fig. (1). One example could be the WavePlane converter.

In general, as noted above, these devices are in early stages compared with conventional fossil plants, and most importantly, there is still no design outweighing overwhelms the rest. However there is a tendency [8] by companies that recently more point absorber type WECs are developed. It may indicate that it is less complex and expensive than other technologies.

\section{HYBRID WIND-WAVE ENERGY SYSTEM}

As mentioned above, by combing wave energy converter with floating wind turbine, some disadvantages hinder WEC can be solved [9-12]. The overall cost can be decreased when mooring system, electrical infrastructure like cable can be shared. The ideally choose of WEC, the overall motion performance can be more stable which will lead a greater power performance and motion reflection in survival condition. However, it is still very difficult to choose a proper WEC for the hybrid system. The followings are some related discussion about WEC selection for hybrid system.
For location classification, offshore WEC devices are definitely more suitable for hybrid system than onshore or near-shore devices since most floating wind turbines work offshore for the higher quality energy source.

For size classification, the advantages of point absorber also make it a relatively reasonable choice for hybrid system. For offshore wind turbines in a farm, each device should be spaced at a certain distance to account aerodynamic wake effect. In this term, placing point absorbers in the spaces of a wind farm seems like a more proper option.

For work principle classification, the oscillating body system shows advantages than the other two types of WECs. Since the oscillating body system has many subcategories with different motion performances and combining forms (floating or submerged; one body, two bodies or even many bodies; heave, pitch or surge). This diversity makes oscillating body system more flexible when integrated with floating support platform than OWC and overtopping converter.

Actually, each category of WEC has quite different feature and there is still no common sense about which kind of WEC should be the best choice or has obvious advantage over others. In addition, WEC's performance also varies when coupled with different floating platforms. However, based on above comment, the three outstanding subcategories among the three different classifications (working principle, location and size) are respectively oscillating body system, offshore device and point absorber. These are just three features of WEC, not definitely three separate devices. It still depends on different specific situations and considerations. Followings are several examples illustrating how WECs are integrated into the hybrid systems.

\subsection{Spar-Torus Combination (STC)}

In this combination, a point absorber type WEC (Wavebob) is integrated with the spar type floating wind turbine (Hywind). As simply sketched in Fig. (2), A1 is the spar type floating wind turbine, A2 is the hybrid system Spar-Torus Combination (STC). In this concept, the point absorber will slide along the Spar to extract energy from waves while the wind turbine generates power from the wind. In this way, the point absorber will benefit from using the FWT's mooring system as well as power cable.
A1

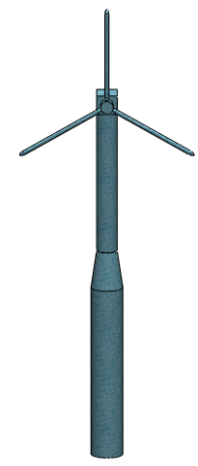

A2

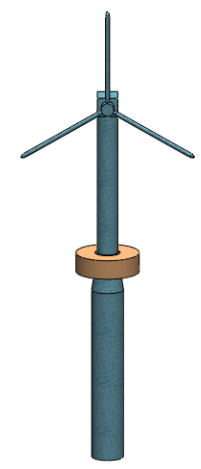

Fig. (2). Simplified sketch for STC (A1-Spar Type FWT; A2-STC). 
B1

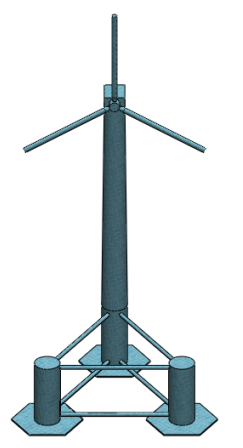

B2

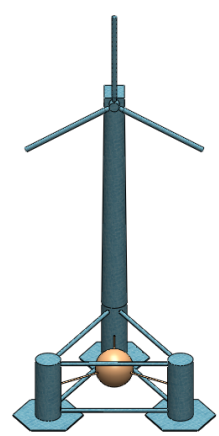

B3

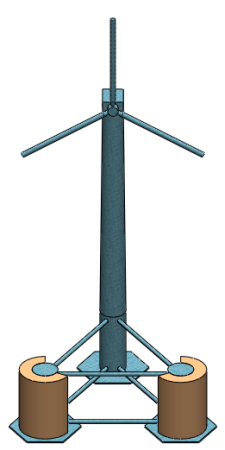

B4

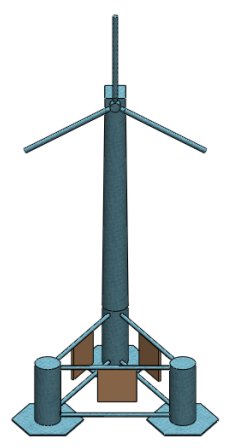

Fig. (3). Simplified sketch for wind wave float (B1-Tri-floater Type FWT; B2-Tri-floater and a point absorber; B3-Tri-floater and two OWC; B4-Tri-floater and three oscillating surge converter).

Related to this project, there are several papers presenting its details including numerical simulation of the hybrid system in operational and survival mode [13], model experimental test for survival modes [14]. Power take-off and mooring systems analysis are carried out for two-body floating WEC used in the hybrid system [15]. The related dynamic response of the spar-type wind turbine is also presented [16]. The recent results show that STC has more stable motion performance and greater power output than Spar only situation.

In this combination, the point absorber and spar type floating platform are both simple and fully developed concepts. The simplification in design makes the STC easier to be modeled in numerical simulation and further validation. However, many challenges still remain related to the feasibility of the STC.

\subsection{Wind Wave Float}

In this combination, point absorber, OWC and oscillating wave surge converter are integrated with a tri-floater type floating wind turbine respectively, as shown in Fig. (3).

Firstly, a point absorber, called SWEDE, is placed within the WindFloat platform as shown in B2 of Fig. (3). The SWEDE is attached to the WindFloat by three lines. A spherical floater was chosen because it responds well in heave, with very little pitch motion.

Secondly, two oscillating wave column (OWC) is installed on the spare columns of WindFloat on which there is not placed a wind turbine platform as shown in B3 of Fig. (3). In the OWC, water enters through a subsurface opening into a chamber that contains air. The wave's up-and-down action causes the captured water column to rise and fall like a piston, compressing and decompressing the air. As a result, an air flow moves back and forth through a turbine coupled to an electric generator.

Thirdly, three hinged rectangular flaps (flat stiffened vertical plates, oscillating surge converter) are installed on the top main beams of the WindFloat platform as shown in B4 of Fig. (3). The flaps oscillate back and forth as they are motivated by incoming waves. More details of the three different combinations of WindWaveFloat concepts can be found in [17-20].
In this project, both numerical calculation and experimental analysis are carried out and some typical differences have been highlighted among the results comparison in both experimental and numerical analysis. These comparisons include, but are not limited to, the difference of platform motion after adding WEC, the difference of WEC motion when the platform is floating and fixed, the difference of the whole system motion in all wave directions. The comparison results show the feasibility of WindWaveFloat and its value for further optimization. Even though more studies need to be carried out to further assess the hybrid device's performance, the WindWaveFloat fully illustrates the potential possibility of the tri-floater platform structure.

\section{CONCLUSION}

In this paper, all subcategories of wave energy converter are fully illustrated with its potential and limitation. Then a new hybrid concept combining wave energy converter with floating wind turbine is presented which seems can improve the overall power and motion performance and also the costbenefit. Several existing hybrid systems are exampled to show how WEC are be integrated into the support floating platform. Additionally, for WEC application in hybrid system, a temporary conclusion has been made that offshore, point absorber and oscillating body system are three more suitable features in three classification methods (respectively location, size and work principle).

\section{CONFLICT OF INTEREST}

The author confirms that this article content has no conflict of interest.

\section{ACKNOWLEDGEMENTS}

Declared none.

\section{REFERENCES}

[1] R. Pelc and R. M. Fujita, "Renewable energy from the ocean", Marine Policy, vol. 26, no. 6, pp. 471-479, 2002.

[2] R. A. González, "Tecnologías para el aprovechamiento de la energía de las olas y de las corrientes marinas", Boletín de inteligencia tecnológica, pp. 1-28, 2009. 
[3] Y. Li and Y. H. Yu, "A synthesis of numerical methods for modeling wave energy converter-point absorbers", Renewable and Sustainable Energy Reviews, vol. 16, no. 6, pp. 4352-4364, 2012.

[4] D. V. Evans, "Power from water waves", Annual review of Fluid mechanics, vol. 13, no. 1, pp. 157-187, 1981.

[5] F. D. O. Antonio, "Wave energy utilization: A review of the technologies", Renewable and sustainable energy reviews, vol. 14, no. 3, pp. 899-918, 2010.

[6] A. J. N. A. Sarmento, F. Neumann, and A. Brito-Melo, "Nontechnical barriers to large-scale wave energy utilisation", in New and renewable energy technologies for sustainable development, Evora international conference on new and renewable energy technologies for sustainable development, Evora, Portugal, vol. 28, pp. 225-233, June 2007.

[7] J. Falnes, "A review of wave-energy extraction", Marine Structures, vol. 20, no. 4, pp. 185-201, 2007.

[8] I. López, J. Andreu, S. Ceballos, I. M. de Alegría, and I. Kortabarria, "Review of wave energy technologies and the necessary power-equipment", Renewable and Sustainable Energy Reviews, vol. 27, pp. 413-434, 2013.

[9] A. Peiffer, D. Roddier, and A. Aubault, "Design of a point absorber inside the WindFloat structure", in ASME $30^{\text {th }}$ International Conference on Ocean, Offshore and Arctic Engineering, American Society of Mechanical Engineers, pp. 247-255, January 2011

[10] A. Aubault, M. Alves, A. Sarmento, D. Roddier, and A. Peiffer, "Modeling of an oscillating water column on the floating foundation WindFloat", in ASME $201130^{\text {th }}$ International Conference on Ocean, Offshore and Arctic Engineering, American Society of Mechanical Engineers, pp. 235-246, January 2011.

[11] Z. L. Liu, "Review on Regional and spatial-economic impact from high speed Rails", African journal of Business Management, vol. 6, no. 35, pp. 9738-9741, 2012. doi: 10.5897/ajbm12.859

[12] D. Roddier, A. Peiffer, A. Aubault, and J. Weinstein, "A generic 5 MW WINDFLOAT for numerical tool validation \& comparison against a generic spar", in ASME $30^{\text {th }}$ International Conference on Ocean, Offshore and Arctic Engineering, OMAE 2011.

[13] M. J. Muliawan, M. Karimirad, and T. Moan, "Dynamic response and power performance of a combined spar-type floating wind turbine and coaxial floating wave energy converter", Renewable Energy, vol. 50, pp. 47-57, 2013.

[14] M. J. Muliawan, M. Karimirad, and T. Moan, "Dynamic response and power performance of a combined spar-type floating wind turbine and coaxial floating wave energy converter", Renewable Energy, vol. 50, pp. 47-57, 2013.

[15] M. J. Muliawan, M. Karimirad, Z. Gao, and T. Moan, "Extreme responses of a combined spar-type floating wind turbine and floating wave energy converter (STC) system with survival modes", Ocean Engineering, vol. 65, pp. 71-82, 2013.

[16] J. Weber, F. Mouwen, A. Parish, and D. Robertson, "Wavebobresearch \& development network and tools in the context of systems engineering", in Proc. Eighth European Wave and Tidal Energy Conference, Uppsala, Sweden, 2009.

[17] M. Karimirad and T. Moan, "Wave-and wind-induced dynamic response of a spar-type offshore wind turbine", Journal of waterway, port, coastal, and ocean engineering, vol. 138, no. 1, pp. 9-20, 2011.

[18] L. Wan, Z. Gao, and T. Moan, "Model Test of the STC Concept in Survival Modes", in ASME $201433^{\text {rd }}$ International Conference on Ocean, Offshore and Arctic Engineering, American Society of Mechanical Engineers, pp. V09AT09A010-V09AT09A010, 2014

[19] M. J. Muliawan, Z. Gao, T. Moan, and A. Babarit, "Analysis of a two-body floating wave energy converter with particular focus on the effects of power take-off and mooring systems on energy capture", Journal of off shore Mechanics and Arctic Engineering, vol. 135 , no. 3,2013 .

[20] D. Roddier, C. Cermelli, A. Aubault, and A. Weinstein, "WindFloat: A floating foundation for offshore wind turbines", Journal of Renewable and Sustainable Energy, vol. 2, no. 3, 2010. 